Леса России и хозяйство в них. 2021. № 3. С. 38-47.

Forests of Russia and economy in them. 2021. № 3. P. 38-47.

Научная статья

УДК 630*223:630*24:630*57:

doi: 10.51318/FRET.2021.66.66.005

\title{
ОСОБЕННОСТИ ЕСТЕСТВЕННОГО ЛЕСОВОЗОБНОВЛЕНИЯ ГАРИ УРАЙСКОГО ЛЕСНИЧЕСТВА ХМАО
}

\author{
Алексей Анатольевич Носов ${ }^{1}$, Анастасия Васильевна Данчева ${ }^{2}$ \\ 1,2 Государственный аграрный университет Северного Зауралья, Тюмень, Россия \\ 1'nosov.aa@mti.gausz.ru \\ 2a.dancheva@mail.ru, https://orcid.org/0000-0002-5230-7288
}

\begin{abstract}
Аннотация. Приведены данные исследований естественного лесовозобновления гари в условиях Западно-Сибирского среднетаежного равнинного лесного района таежной лесорастительной зоны (на примере Урайского лесничества, расположенного в юго-западной части Ханты-Мансийского автономного округа - Югры на территории Кондинского административного района). Оценка лесовозобновления проведена по методу учетных лент, заложенных на расстоянии 50 и 100 м от стены леса. Данные исследований показали непрерывность лесовосстановительного процесса на гари. Отмечается наличие всходов, самосева и подроста высотных категорий «мелкий», «средний» и «крупный». Лесовозобновление гари происходит двумя древесными породами - сосной и березой. По существующим нормативам возобновление сосны оценивается как хорошее. По количеству всходов и подроста преобладает сосна. При удалении от стены леса на 100 м происходит уменьшение количества всходов и подроста всех категорий крупности в 2-3 раза в сравнении с аналогичными показателями на расстоянии 50 м от стены леса независимо от вида древесной породы. Во всех высотных категориях отмечается преобладание жизнеспособного подроста сосны - до 90-100 \%, что является основным показателем успешности лесовосстановления исследуемой гари на данном этапе развития. Береза в большинстве случаев представлена сомнительными по жизнеспособности экземплярами. В качестве лесохозяйственных мероприятий можно предложить проведение мониторинга за состоянием подроста и уходные мероприятия за подростом.

Ключевые слова: гарь, естественное лесовозобновление, древесные породы, показатели подроста.
\end{abstract}

Scientific article

\section{FEATURES OF REFORESTATION OF BURNED AREAS IN THE URAISK FORESTRY DEPARTMENT OF THE KHANTY-MANSI AUTONOMOUS AREA}

\author{
Alexey Anatolyevich Nosov ${ }^{1}$, Anastasia Vasilyevna Dancheva ${ }^{2}$, \\ ${ }^{1,2}$ Northern Trans-Ural State Agricultural University, Tyumen, Russia \\ ${ }^{1}$ nosov.aa@mti.gausz.ru \\ 2a.dancheva@mail.ru, https://orcid.org/0000-0002-5230-7288
}

\begin{abstract}
Annotation. The results of features formations of post-fire pine undergrowth on burnt area of the middle taiga zone of Western Siberia (for example, Uraisk forestry department) in location of the Khanty-Mansi Autonomous Area. Undergrowth was studied on tapes laid out parallel to the forest edges at a distance of 50
\end{abstract}

(C) Носов А. А., Данчева А. В., 2021 
and 100. According to studies it is observed of reafforestation continuity of burned areas. The presence of sprouting and undergrowth of the high- elevation categories «small», «medium» and «large» is noted. The burned areas reforestation with two tree species - pine and birch proceed. According to current specification, the pine natural regeneration is assessed as «normal». The amount of pine undergrowth is greater than the amount of birch undergrowth. To be at $100 \mathrm{~m}$ from forest edges the number of seedlings and undergrowth decreases by $2-3$ times in comparison with the same indicators at $50 \mathrm{~m}$ from the forest edges. There is a predominance of vital pine undergrowth - up to $90-100 \%$. This is evidence of the successful reforestation of burned areas at this stage of development.

Keywords: burnt area, natural reafforestation, tree species, undergrowth indicators.

\section{Введение}

Процесс естественного возобновления в лесах - важнейший показатель эволюции, тесно связанный с этапами их формирования [1-3]. Одним из наиболее актуальных вопросов в современном ведении лесного хозяйства является изучение послепожарной динамики лесов. Это связано с необходимостью составления прогноза особенностей лесообразовательного процесса на гарях в различных лесорастительных условиях и моделирования изучения динамики лесного покрова после огневого воздействия $[4,5]$. Процесс естественного лесовозобновления на «свежих» гарях отражает степень адаптации к резко изменившимся лесорастительным условиям, а также стабильность лесной экосистемы в сложившихся антропогенных условиях [6]. Изучение процессов естественного лесовозобновления и формирования молодняков на гарях имеет большое практическое значение для своевременного проведения необходимых лесоводственных мероприятий [7-10]. Периодически повторяющиеся лесные пожары являются одним из важнейших экологических факторов, оказывающих трансформирующее воз- действие на структуру, функции, динамику и эволюцию всех компонентов лесных экосистем [11]. Скорость и потенциальная возможность восстановления леса после пожара зависят от времени пожара, его вида, интенсивности, типа леса и других факторов $[12,13]$.

Так, исследования, проведенные в сосняках черничных и брусничных Ленинградской области, показали, что естественное их возобновление после низовых пожаров происходит успешно на площади до 0,3 га. Количество жизнеспособного подроста составляет 3,5-12,0 тыс. шт./га, что является достаточным условием для естественного восстановления ценопопуляции после пожаpa [14].

Исследования, проведенные на гарях в ленточных борах Прииртышья, свидетельствуют об особенностях их лесовозобновления, заключающихся в более позднем, чем в таежной зоне, естественном изреживании сосновых молодняков, формирующихся на гарях; происходит это при густоте подроста более 3,6 тыс. экз/га $[15,16]$.

Изучение особенностей послепожарного возобновления лиственничников в условиях сред- ней тайги показало, что после пожаров слабой силы количество подроста лиственницы увеличивается по сравнению с его допожарным количеством. При этом породный состав послепожарного подроста полностью соответствует составу родительского древостоя [17]. Установлено, что сильные пожары в большинстве случаев губительны для северных лесных экосистем; слабые и средние по силе пожары могут иметь позитивное экологическое значение.

По данным ряда авторов [18], на гарях в условиях лесостепи в сухих лесорастительных условиях формируются смешанные сосново-березовые молодняки. Присутствие в составе формирующихся послепожарных молодняков подроста березы положительно влияет на рост и развитие главной породы-лесообразователя. Последующее регулирование густоты рубками ухода позволит предотвратить отпад деревьев, обеспечит максимальный средний прирост по высоте и диаметру, а также высокие показатели жизненного состояния формирующихся молодняков [13, 19].

Исследования лесовозобновительного процесса в дубравах 
Воронежской области свидетельствуют о положительном воздействии пирогенного фактора на вегетативное возобновление дуба черешчатого. При этом отмечается особенность более интенсивной порослевой способности данных насаждений в худших лесорастительных условиях [20].

Таким образом, вопрос естественного лесовозобновления и лесовосстановления лесных участков, пройденных лесными пожарами, является актуальной темой исследований на сегодняшний день на всей территории РФ и за ее пределами, поскольку от специфики лесовозобновительных процессов на рассматриваемых территориях зависят качественные и количественных показатели будущих лесных насаждений.

\section{Объекты}

\section{и методы исследования}

Впервые были проведены исследования особенностей лесовозобновления гарей в Урайском лесничестве, расположенном в юго-западной части Ханты-Мансийского автономного округа - Югры на территории Кондинского административного района (рисунок).

Леса лесничества отнесены к Западно-Сибирскому среднетаежному равнинному лесному району таежной лесорастительной зоны [21]. По данным лесного фонда, по состоянию на 01.01.2020 г. общая площадь Урайского лесничества составляет 534259 га.

На покрытую лесом площадь приходится 57,5 \% всей территории лесничества. Основными лесообразующими древесными породами в Урайском лесничестве являются сосна и береза. По площади преобладают хвойные насаждения - до $61,5 \%$ от общей покрытой лесом площади. Из хвойных пород преобладает сосна - до 86 \% площади хвойных насаждений. На долю кедра и ели приходится 10,0 и 3,0 \% соответственно. Насаждения пихты и лиственницы не превышают $1 \%$ от общей площади хвойных лесов.

Из лиственных пород преобладает береза - $90 \%$ от общей площади мягколиственных насаждений. Также встречаются осиновые насаждения, площадь которых не превышает $10 \%$.

Объектом исследований являлась гарь площадью 4,0 га в квартале 451 выделе 92 Урайского лесничества Ханты-Мансийско-

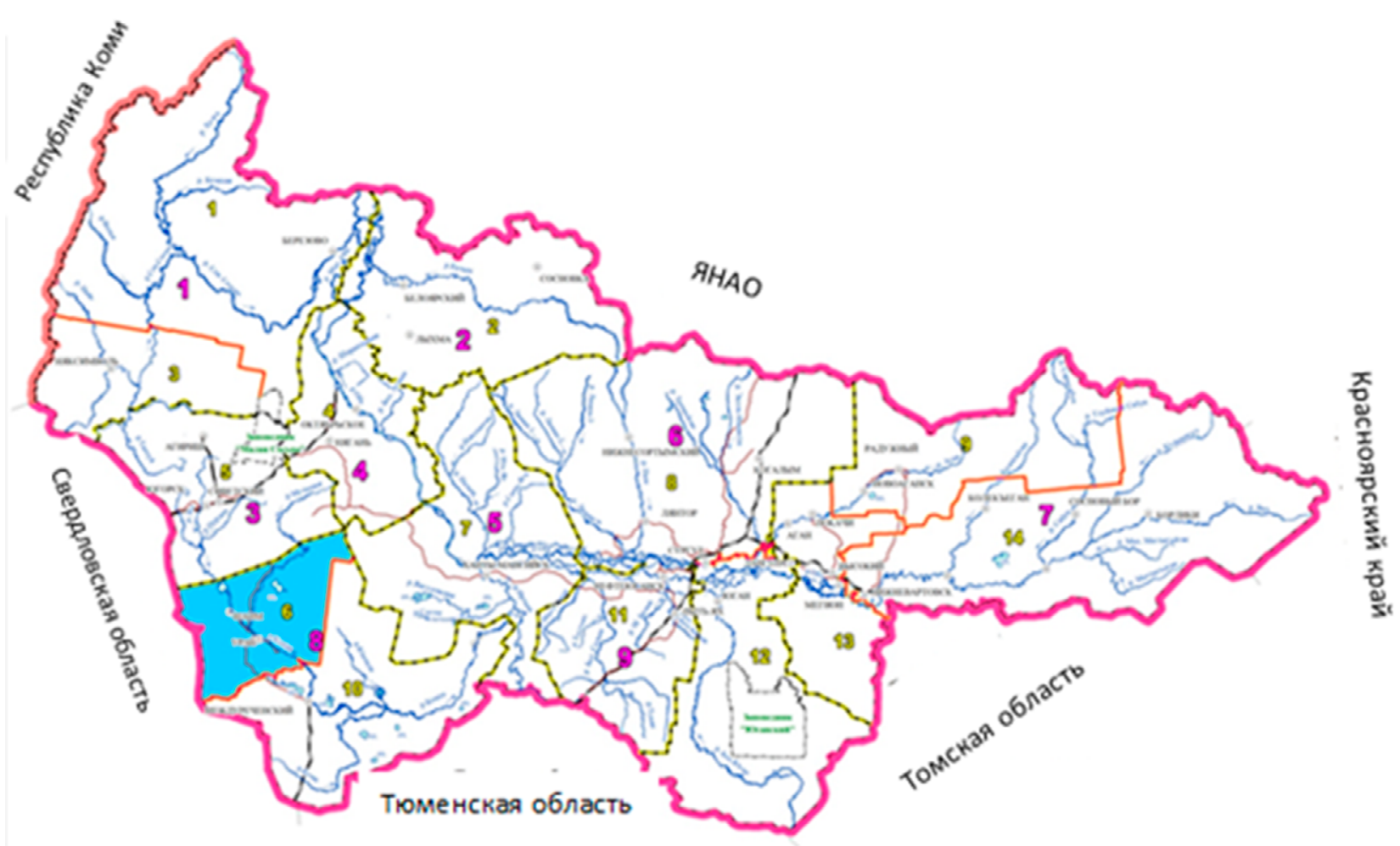

Расположение Урайского лесничества (обозначено голубым цветом) на территории ХМАО Location of the Urayskoye forestry (marked in blue) on the Khanty-Mansi Autonomous Okrug 
го автономного округа - Югры (XMAO). Пожар был обнаружен 25.04.2010 г. Вид пожара - низовой устойчивый. Мероприятия, проведённые для тушения: заливка водой, засыпка грунтом, расчистка валежника. На территории гари проходит естественное лесовосстановление.

При проведении исследований лесовосстановления гари использовалась стандартная методика [22], заключающаяся в следующем: на расстоянии 50 и 100 м от стены леса были заложены учётные ленты. На каждой учетной ленте закладывались 10 учетных площадок площадью $2 \times 2$ м $^{2}$. На каждой учетной площадке был проведен подсчёт возобновления (всходы и подрост) отдельно по породам. В ходе исследований подрост был распределен по высотным категориям: мелкий $(0-0,5$ м), средний $(0,5-1,0$ м), крупный (свыше 1,0 м). Каждому экземпляру подроста была дана оценка его жизнеспособности. Жизнеспособность подроста определялась визуально по следующим критериям: жизнеспособный (Ж) - полностью здо- ровый на вид, без пожелтений и болезней; сомнительный (C) - на листве (хвое) имеются пожелтения, поврежденный стволик, объедание листвы и признаки ослабления состояния растения, нежизнеспособный (НЖ) - засохший (погибший).

Возраст подроста определялся по количеству мутовок.

\section{Результаты исследования}

Полученные данные по перечету всходов и подроста на учетных площадках представлены в табл. 1.

Таблица 1

Table 1

Данные перечета подроста на учетных лентах на гари в Урайском лесничестве

Data on undergrowth indicators on burnt area in Urayskoye forestry

\begin{tabular}{|c|c|c|c|c|c|c|c|c|c|c|c|}
\hline \multirow{3}{*}{$\begin{array}{c}\text { № } \\
\text { учет. площ. } \\
\text { № } \\
\text { account } \\
\text { platform. }\end{array}$} & \multirow{3}{*}{$\begin{array}{c}\text { Древесная } \\
\text { порода } \\
\text { Tree breed }\end{array}$} & \multirow{3}{*}{$\begin{array}{c}\text { Всходы, } \\
\text { шт. } \\
\text { Shoots, } \\
\text { pcs. }\end{array}$} & \multicolumn{9}{|c|}{$\begin{array}{l}\text { Распределение подроста по группам высот, см } \\
\text { Distribution of undergrowth by height groups, cm }\end{array}$} \\
\hline & & & \multicolumn{3}{|c|}{$\begin{array}{c}\text { Мелкий } \\
\text { (до 0,5 м) } \\
\text { Shallow } \\
\text { (up to } 0,5 \text { m) }\end{array}$} & \multicolumn{3}{|c|}{$\begin{array}{c}\text { Средний } \\
(0,5-1,0 \text { м) } \\
\text { Medium } \\
(0,5-1,0 \text { m) }\end{array}$} & \multicolumn{3}{|c|}{$\begin{array}{c}\text { Крупный } \\
\text { (свыше 1,0 м) } \\
\text { Large } \\
\text { (over } 1,0 \mathrm{~m} \text { ) }\end{array}$} \\
\hline & & & $\begin{array}{c}\text { Ж } \\
\mathrm{L}\end{array}$ & $\begin{array}{l}C \\
D\end{array}$ & $\begin{array}{l}\text { HЖ } \\
\text { NV }\end{array}$ & $\begin{array}{c}\text { Ж } \\
\mathrm{L}\end{array}$ & $\begin{array}{l}\mathrm{C} \\
\mathrm{D}\end{array}$ & $\begin{array}{l}\mathrm{H} \text { - } \\
\mathrm{NV}\end{array}$ & $\begin{array}{c}\text { Ж } \\
\mathrm{L}\end{array}$ & $\begin{array}{l}\text { C } \\
\mathrm{D}\end{array}$ & $\begin{array}{l}\mathrm{H} \text { } \\
\mathrm{NV}\end{array}$ \\
\hline \multicolumn{12}{|c|}{$\begin{array}{l}\text { Расстояние } 50 \text { м от стены леса } \\
\text { Distance } 50 \mathrm{~m} \text { from the forest wall }\end{array}$} \\
\hline \multirow{2}{*}{1} & $\mathrm{C}$ & 11 & 3 & - & - & 3 & - & - & 5 & - & - \\
\hline & Б & 5 & - & 1 & - & 3 & - & - & 1 & - & - \\
\hline \multirow{2}{*}{2} & $\mathrm{C}$ & 14 & 1 & - & - & 6 & - & - & 7 & - & - \\
\hline & Б & 5 & - & - & - & 4 & - & - & 1 & - & - \\
\hline \multirow{2}{*}{3} & $\mathrm{C}$ & 10 & 2 & - & - & - & - & - & 8 & - & - \\
\hline & Б & 3 & 1 & - & - & 1 & - & - & 1 & - & - \\
\hline \multirow{2}{*}{4} & $\mathrm{C}$ & 6 & 3 & - & - & 3 & - & - & - & - & - \\
\hline & Б & 1 & - & - & - & 1 & - & - & - & - & - \\
\hline \multirow{2}{*}{5} & $\mathrm{C}$ & 9 & 3 & - & - & 2 & - & - & 4 & - & - \\
\hline & Б & 3 & 2 & - & - & 1 & - & - & - & - & - \\
\hline \multirow{2}{*}{6} & $\mathrm{C}$ & 7 & - & - & - & 4 & - & - & 3 & - & - \\
\hline & Б & 1 & - & 1 & - & - & - & - & - & - & - \\
\hline \multirow{2}{*}{7} & $\mathrm{C}$ & 12 & - & - & - & 7 & - & - & 5 & - & - \\
\hline & Б & 5 & - & - & - & 2 & - & - & 3 & - & - \\
\hline
\end{tabular}


Окончание табл. 1

The end of table 1

\begin{tabular}{|c|c|c|c|c|c|c|c|c|c|c|c|}
\hline \multirow{3}{*}{$\begin{array}{c}\text { № } \\
\text { учет. площ. } \\
\text { № } \\
\text { account } \\
\text { platform. }\end{array}$} & \multirow{3}{*}{$\begin{array}{l}\text { Древесная } \\
\text { порода } \\
\text { Tree breed }\end{array}$} & \multirow{3}{*}{$\begin{array}{l}\text { Всходы, } \\
\text { шт. } \\
\text { Shoots, } \\
\text { pcs. }\end{array}$} & \multicolumn{9}{|c|}{$\begin{array}{l}\text { Распределение подроста по группам высот, см } \\
\text { Distribution of undergrowth by height groups, cm }\end{array}$} \\
\hline & & & \multicolumn{3}{|c|}{$\begin{array}{c}\text { Мелкий } \\
\text { (до 0,5 м) } \\
\text { Shallow } \\
\text { (up to } 0,5 \mathrm{~m} \text { ) }\end{array}$} & \multicolumn{3}{|c|}{$\begin{array}{c}\text { Средний } \\
(0,5-1,0 \mathrm{~m}) \\
\text { Medium } \\
(0,5-1,0 \mathrm{~m}) \\
\end{array}$} & \multicolumn{3}{|c|}{$\begin{array}{c}\text { Крупный } \\
\text { (свыше 1,0 м) } \\
\text { Large } \\
\text { (over } 1,0 \text { m) }\end{array}$} \\
\hline & & & $\begin{array}{l}\text { Ж } \\
\mathrm{L}\end{array}$ & $\begin{array}{l}\mathrm{C} \\
\mathrm{D}\end{array}$ & $\begin{array}{l}\mathrm{H} \\
\mathrm{NV}\end{array}$ & $\begin{array}{l}\text { Ж } \\
\mathrm{L}\end{array}$ & $\begin{array}{l}\mathrm{C} \\
\mathrm{D}\end{array}$ & $\begin{array}{l}\mathrm{H} \\
\mathrm{NV}\end{array}$ & $\begin{array}{c}\text { Ж } \\
\mathrm{L}\end{array}$ & $\begin{array}{l}\mathrm{C} \\
\mathrm{D}\end{array}$ & $\begin{array}{l}\mathrm{H} \\
\mathrm{NV}\end{array}$ \\
\hline \multirow{2}{*}{8} & $\mathrm{C}$ & 8 & 2 & - & - & 4 & - & - & 2 & - & - \\
\hline & Б & 1 & - & 1 & - & - & - & - & - & - & - \\
\hline 9 & $\mathrm{C}$ & 10 & 5 & - & - & 3 & - & - & 2 & - & - \\
\hline 10 & $\mathrm{C}$ & 7 & 2 & - & - & 4 & - & - & 1 & - & - \\
\hline \multicolumn{2}{|c|}{$\begin{array}{c}\text { Всего } \\
\text { Aggregate }\end{array}$} & 118 & 24 & 3 & - & 48 & - & - & 43 & - & - \\
\hline \multicolumn{12}{|c|}{$\begin{array}{l}\text { Расстояние } 100 \text { м от стены леса } \\
\text { Distance } 100 \mathrm{~m} \text { from the forest wall }\end{array}$} \\
\hline \multirow{2}{*}{1} & $\mathrm{C}$ & 7 & - & - & - & 2 & - & - & 5 & - & - \\
\hline & Б & 1 & 1 & - & - & - & - & - & - & - & - \\
\hline 2 & $\mathrm{C}$ & 10 & - & - & - & 5 & - & - & 5 & - & - \\
\hline 3 & $\mathrm{C}$ & 6 & 2 & - & - & 4 & - & - & - & - & - \\
\hline 4 & $\mathrm{C}$ & 8 & 1 & - & - & 5 & - & - & 2 & - & - \\
\hline 5 & $\mathrm{C}$ & 11 & 4 & - & - & 3 & - & - & 4 & - & - \\
\hline \multirow{2}{*}{6} & $\mathrm{C}$ & 9 & - & - & - & 4 & - & - & 5 & - & - \\
\hline & Б & 4 & - & 1 & - & 3 & - & - & - & - & - \\
\hline \multirow{2}{*}{7} & $\mathrm{C}$ & 10 & 1 & - & - & 7 & - & - & 2 & - & - \\
\hline & Б & 2 & - & - & - & 2 & - & - & - & - & - \\
\hline 8 & $\mathrm{C}$ & 5 & 1 & - & - & 3 & - & - & 1 & - & - \\
\hline 9 & $\mathrm{C}$ & 4 & - & - & - & 2 & - & - & 2 & - & - \\
\hline 10 & $\mathrm{C}$ & 8 & 2 & - & - & 3 & - & - & 3 & - & - \\
\hline \multicolumn{2}{|c|}{$\begin{array}{c}\text { Всего } \\
\text { Aggregate }\end{array}$} & 85 & 12 & 1 & - & 43 & - & - & 29 & - & - \\
\hline
\end{tabular}

Примечание. Ж - жизнеспособный, C - сомнительный, НЖ - нежизнеспособный. Note. $\mathrm{L}$ - viable, D - doubtful, NV - not viable.

Данные, представленные в табл. 1, были сгруппированы по количественным и качественным показателям подроста каждой высотной категории и рассчитаны их средние значения, которые указаны в табл. 2.

По данным табл. 2 исследуемая гарь возобновляется двумя древесными породами - сосной и березой, при этом во всех высотных категориях преобладает подрост сосны.

Всходы представлены древесными породами - сосной и березой. По общему их количеству преобладает сосна - в 4-10 раз в сравнении с аналогичным показателем березы. Отмечается снижение количества всходов с удалением от стены леса. Так, если на расстоянии 50 м количество всходов сосны и березы составляло 23,5 и 6,0 тыс. шт./га соответственно, то на расстоянии 100 м - 19,5 и 1,8 тыс. шт./га, т. е. в 1,2-3 раза меньше.

Аналогичная ситуация наблюдается при анализе подроста каждой высотной категории. Так, 
Таблица 2

Table 2

Среднее количественные и качественные показатели естественного возобновления гари, тыс. шт./га

Mean values of natural reafforestations indicators of burnt area, thousand pieces/ha

\begin{tabular}{|c|c|c|c|c|c|c|c|c|c|c|c|c|c|c|c|c|}
\hline \multirow{3}{*}{$\begin{array}{c}\text { Поро- } \\
\text { да } \\
\text { Tree } \\
\text { breed }\end{array}$} & \multirow{3}{*}{$\begin{array}{c}\text { Всходы } \\
\text { Shoots, } \\
\text { pcs. }\end{array}$} & \multicolumn{12}{|c|}{$\begin{array}{c}\text { Количество подроста на } 1 \text { га, тыс. шт. } \\
\text { Distribution of undergrowth by height groups, cm }\end{array}$} & \multirow{2}{*}{\multicolumn{3}{|c|}{$\begin{array}{l}\text { Bсего } \\
\text { In total }\end{array}$}} \\
\hline & & \multicolumn{4}{|c|}{$\begin{array}{c}\text { Мелкий } \\
\text { (до 0,5 м) } \\
\text { Shallow } \\
\text { (up to } 0,5 \mathrm{~m} \text { ) }\end{array}$} & \multicolumn{4}{|c|}{$\begin{array}{c}\text { Средний } \\
(0,5-1,0 \text { м) } \\
\text { Medium } \\
(0,5-1,0 \mathrm{~m})\end{array}$} & \multicolumn{4}{|c|}{$\begin{array}{c}\text { Крупный } \\
\text { (свыше 1,0 м) } \\
\text { Large } \\
\text { (over } 1,0 \mathrm{~m} \text { ) }\end{array}$} & & & \\
\hline & & $\begin{array}{l}\text { Ж } \\
\mathrm{L}\end{array}$ & $\begin{array}{l}\mathrm{C} \\
\mathrm{D}\end{array}$ & $\begin{array}{c}\mathrm{H} \\
\mathrm{NV}\end{array}$ & $\begin{array}{l}\text { Итого } \\
\text { In total }\end{array}$ & $\begin{array}{l}\text { Ж } \\
\mathrm{L}\end{array}$ & $\begin{array}{l}\mathrm{C} \\
\mathrm{D}\end{array}$ & $\begin{array}{l}\text { HЖ } \\
\mathrm{NV}\end{array}$ & $\begin{array}{l}\text { Итого } \\
\text { In total }\end{array}$ & $\begin{array}{c}\text { Ж } \\
\mathrm{L}\end{array}$ & $\begin{array}{l}\mathrm{C} \\
\mathrm{D}\end{array}$ & $\begin{array}{l}\text { HЖ } \\
\text { NV }\end{array}$ & $\begin{array}{l}\text { Итого } \\
\text { In total }\end{array}$ & $\begin{array}{l}\text { Ж } \\
\mathrm{L}\end{array}$ & $\begin{array}{l}\mathrm{C} \\
\mathrm{D}\end{array}$ & $\begin{array}{l}\text { HЖ } \\
\text { NV }\end{array}$ \\
\hline \multicolumn{17}{|c|}{$\begin{array}{l}\text { Расстояние } 50 \text { м от стены леса } \\
\text { Distance } 50 \mathrm{~m} \text { from the forest wall }\end{array}$} \\
\hline $\mathrm{C}$ & 23,5 & 5,2 & - & - & 5,5 & 9,0 & - & - & 9,0 & 9,2 & - & - & 9,2 & 23,5 & - & - \\
\hline Б & 6,0 & 0,8 & 0,7 & - & 1,6 & 3,0 & - & - & 3,0 & 1,5 & - & - & 1,5 & 5,2 & 0,7 & - \\
\hline \multicolumn{17}{|c|}{$\begin{array}{l}\text { Расстояние } 100 \text { м от стены леса } \\
\text { Distance } 100 \mathrm{~m} \text { from the forest wall }\end{array}$} \\
\hline $\mathrm{C}$ & 19,5 & 2,8 & - & - & 2,8 & 9,5 & - & - & 9,5 & 7,2 & - & - & 7,2 & 19,5 & - & - \\
\hline Б & 1,8 & 0,3 & 0,2 & - & 0,5 & 1,2 & - & - & 1,2 & - & - & - & - & 1,5 & 0,2 & - \\
\hline
\end{tabular}

Примечание. Ж - жизнеспособный подрост, С - сомнительный подрост, НЖ - нежизнеспособный подрост.

Note. L - viable, D - doubtful, NV - not viable.

на расстоянии 50 м от стены леса количество мелкого подроста (до 0,5 м) сосны и березы составило 5,5 и 1,6 тыс. шт./га соответственно, что в 2 и 3 раза больше, чем на расстоянии 100 м от стены леса. Стоит отметить, что количество среднего и крупного подроста сосны в 1,5-2 раза превышает таковое в категории «мелкий» независимо от расстояния от стены леса.

На большинстве учетных площадок присутствует только жизнеспособный подрост сосны - до 99 \%, что позволяет сделать предварительный вывод об успешности роста соснового подроста на данном этапе развития.

Другая ситуация наблюдается при анализе жизнеспособности подроста берёзы. В категориях крупности «мелкий» и «средний» преобладает сомнительный по состоянию подрост березы до 80-90 \% от общего его количества.

С увеличением расстояния от стены леса отмечается резкое снижение (в 2,5-3 раза) количества подроста березы, а на расстоянии 100 м от стены леса крупный подрост березы полностью отсутствует. Данный факт может являться подтверждением слабой конкуренции подроста берёзы в борьбе за существование в сравнении с подростом сосны на исследуемой гари и вероятном отсутствии процесса смены пород в будущем, что является важным моментом в лесовосстановлении изучаемого лесного участка.

Средний возраст подроста сосны составляет 6-8 лет, а количество жизнеспособного подроста сосны в рассматриваемых трех высотных категориях на расстоянии 50 м от стены леса составляет в среднем 5,0-9,0 тыс. шт./га и на расстоянии 100 м - 3,07,0 тыс. шт./га (см. табл. 2). По шкале Нестерова [22] лесовозобновление гари сосной оценивается как хорошее. Возобновление березы оценивается в среднем как плохое.

Для анализа возможных способов лесовосстановления в зависимости от количества жизнеспособного подроста главных древесных пород на исследуемой гари использовали действующие нормативы, разработанные для отдельных регионов и лесорастительных зон по группам типов леса и лесорастительным условиям [23]. По данным проведенных исследований, количество жизнеспособного подроста сосны на расстоянии 50 и 100 м 
от стены леса превышает нормативные показатели в 3-4 раза, что является достаточным условием для процесса естественного лесовосстановления изучаемой гари на данном этапе роста и развития молодого поколения леса. Дополнительные меры по лесовосстановительным работам на изучаемом участке не нужны. В дальнейшем необходимо проводить мониторинг состояния подроста и осуществлять уходные мероприятия за подростом.

Выводы
1. Лесовозобновление гари
происходит двумя древесными

породами - сосной и березой. По количеству всходов и подроста преобладает сосна. При удалении от стены леса на 100 м происходит уменьшение количества всходов и подроста во всех категориях крупности в 2-3 раза в сравнении с аналогичными показателями на расстоянии 50 м от стены леса независимо от вида древесной породы. Несмотря на снижение количества подроста на расстоянии 100 м от стены леса, лесовозобновление гари по шкале Нестерова характеризуется как хорошее.

2. Во всех высотных категориях отмечается преобладание жизнеспособного подроста со- сны - до 90-100 \%, что является основным показателем успешности лесовосстановления исследуемой гари на данном этапе развития. Береза в большинстве случаев представлена сомнительным по жизнеспособности подростом.

3. В качестве лесохозяйственных мероприятий можно предложить проведение мониторинга за состоянием подроста.

4. Для более детального анализа и получения достоверных данных лесовосстановления лесных участков исследуемого района, пройденных лесными пожарами, необходимо продолжить исследования.

\section{Список источников}

1. Влияние низовых пожаров на формирование светлохвойных насаждений юга Средней Сибири / Л. В. Буряк, А. Г. Лузганов, П. М. Матвеев, О. П. Каленская. Красноярск : СибГТУ, 2003. 195 с.

2. Данчева А. В., Залесов С. В. Динамика естественного возобновления под пологом сосновых насаждений Казахского мелкосопочника // Вестник БГАУ. 2013. № 3. С. 126-128.

3. Залесов С. В. Лесная пирология : учебник для вузов. 3-е изд., перераб. и доп. Екатеринбург : Урал. гос. лесотехн. ун-т, 2013. 333 с.

4. Данилин И. М., Целитан И. А. Закономерности строения и биопродуктивность лиственничного фитоценоза послепожарного формирования в Эвенкии // Пожары в лесных экосистемах Сибири : материалы Всерос. конф. с междунар. участием. Красноярск : Институт леса им. В. Н. Сукачева СО РАН, 2008. C. $109-120$.

5. Данчева А. В., Залесов С. В., Портянко А. В. Особенности формирования ассимиляционного аппарата в послепожарных сосновых молодняках рекреационного назначения // Вестник БГАУ. № 2. $2015 \mathrm{a}$. C. $98-104$.

6. Санников С. Н., Санникова Н. С. Экология естественного возобновления сосны под пологом леса. М. : Наука, 1985. 152 с.

7. Калинин К. К. Естественное лесовозобновление и формирование молодняков в еловых и березовых насаждениях на крупных гарях Среднего Заволжья // Вестник МарГТУ. 2010. № 1. С. 5-15.

8. Данчева А. В., Залесов С. В., Портянко А. В. Биометрические показатели ассимиляционного аппарата в послепожарных сосновых молодняках // Аграрн. вестник Урала. 2015б. № 11 (141). С. 37-41.

9. Лесоводственная эффективность рубок ухода в сосняках Казахского мелкосопочника / С. В. Залесов, А. В. Данчева, А. В. Эбель, Е. И. Эбель // Лесн. жур. 2016а. № 3. С. 21-30.

10. Данчева А. В., Панкратов В. К. Оценка эффективности рубок ухода в сухих сосняках Казахского мелкосопочника // Изв. вузов. Лесн. жур. 2021. № 2. C. 45-55. DOI: 10.37482/0536-1036-2021-2-45-55. 
11. Опыт лесоразведения в сухой типчаково-ковыльной степи Северного Казахстана / С. В. Залесов, Ж. О. Суюндиков, А. В. Данчева, А. Н. Рахимжанов, М. Р. Ражанов // Защитное лесоразведение, мелиорация земель, проблемы агроэкологии и земледелия в Российской Федерации: материалы Междунар. науч.-практ. конф., посвящ. 85-летию создания Всерос. науч.-исслед. агромелиоратив. ин-та, Волгоград, 19-23 сентября 2016 г. Волгоград : ВНИАЛМИ, 2016б. С. 109-113.

12. Шубин Д. А., Малиновских А. А., Залесов С. В. Влияние пожаров на компоненты лесного биогеоценоза в Верхне-Обском боровом массиве // Изв. Оренбургского гос. аграрн. ун-та. 2013. № 6 (44). C. 205-208.

13. Данчева А. В., Залесов С. В. Особенности лесовозобновления гарей в условиях сухих сосняков Казахского мелкосопочника (на примере Баянаульского ГНПП // Изв. СПб лесотехн. акад. 2018. Вып. 224. C. $150-159$.

14. Гусев Д. В. Естественное возобновление сосны после низовых пожаров на территории Ленинградской области // Изв. СПб лесотехн. акад. 2016. Вып. 215. С. 30-40.

15. Данчева А. В., Залесов С. В. Естественное лесовозобновление гарей в условиях сухих сосняков ленточных боров Прииртышья (на примере ГЛПР «Семей орманы») // Успехи современного естествознания. 2017. № 7. C. 24-29.

16. Данчева А. В. Оценка естественного лесовозобновления гарей ленточных боров Прииртышья // Лесоэксплуатация и комплексное использование древесины : сб. ст. Всерос. науч.-практ. конф. Красноярск, 2021. С. 74-79.

17. Матвеев А. М., Матвеев П. М. Влияние огневого воздействия на возобновление среднетаежных лиственничников Эвенкии // Лесоведение. 2006. № 5. С. 7-11.

18. Портянко А. В., Данчева А. В., Залесов С. В. Характеристика крон и стволов деревьев в сосновых молодняках, формирующихся на гарях // Леса России и хоз-во в них. 2014. № 4 (51). С. 14-16.

19. Оценка эффективности рубок ухода в сосняках Казахского мелкосопочника на основе лесоводственного и древесно-кольцевого анализа / А. В. Данчева, М. А. Гурская, С. В. Залесов, Б. М. Муканов // Лесоведение. 2020. № 6. С. 503-514.

20. Галдин В. К., Беспаленко О. Н., Михин В. И. Пирогенные изменения в порослевых дубравах // Лесотехн. жур. 2018. № 4. С. 58-66. DOI: 10.12737/article_5c1a3209194713.59798372.

21. Об утверждении Перечня лесорастительных зон Российской Федерации и Перечня лесных районов Российской Федерации : Министерство природных ресурсов и экологии Российской Федерации № 367 : издан 18.08.2014 : ред. от 19.02.2019 : Зарегистрирован в Минюсте России : 29.09.2014 № 34186 // Консультант плюс. 2019. 32 c. URL: https://www.consultant.ru (дата обращения: 08.09.21).

22. Данчева А. В., Залесов С.В. Экологический мониторинг лесных насаждений рекреационного назначения : учеб. пособие. Екатеринбург : Урал. гос. лесотехн. ун-т, 2015. 152 с.

23. Об утверждении Правил лесовосстановления, состава проекта лесовосстановления, порядка разработки проекта лесовосстановления и внесения в него изменений : Приказ Министерство природных ресурсов и экологии Российской Федерации № 1014 : издан 04.12.2020 : Зарегистрировано в Минюсте России 18.12.2020 № 61556 // Консультант плюс. 2020. 164 c. URL: https://www.consultant.ru (дата обращения: 08.09.21).

\section{References}

1. Impact of surface fires on the light-coniferous forests formation of in the south of Central Siberia / L. V. Buriak, A. G. Luzganov, P. M. Matveev, O. P. Kalenskaya. Krasnoyarsk : SibSTU, 2003. 195 p.

2. Dancheva A. V, Zalesov S. V. Dynamics of natural regeneration of pine plantations under the cover of Kazakh hills // Vestnik of Bashkir State Agrarian University. 2013. Vol. 3. P. 126-128. 
3. Zalesov S. V. Forest pyrology: Textbook for universities. 3rd ed., Rev. and add. Yekaterinburg : Ural. state forestry engineering. un-t, 2013. $333 \mathrm{p}$.

4. Danilin I. M., Tsetlin I. A. Regularities of structure and biological productivity of larch cenosis of postfire formation in Evenkia. Fires in forest ecosystems of Siberia: Proceedings of the All-Russian Conference with international participation. Krasnoyarsk : V. N. Sukachev Forest Institute, 2008. P. 109-120.

5. Dancheva A. V., Zalesov S. V., Portyanko A. V. Peculiarities of assimilative apparatus forming in after-fire burned recreative young pine stands / Vestnik of Bashkir State Agrarian University. 2015a. Vol. 2. P. 98-104.

6. Sannikov S. N., Sannikova N. S. Ecology of natural reafforestation of pine under forest canopy. Moscow : Nauka, 1985. 152 p.

7. Kalinin K. K. Natural reafforestation and young stocks formation in fir and birch plantations at the gross fires of the Central Volga region // Scientific journals of Volga State University of Technology. 2010. Vol. 1. P. 5-15.

8. Dancheva A. V., Zalesov S. V., Portyanko A. V. The biometrics parameters of assimilating apparatus in postfire pine young stands // Agrarian Bulletin of the Urals. 2015b. Vol. 11 (141). P. 37-41.

9. Silvicultural effectiveness of improvement cutting in the pine forests of Kazakh upland / S. V. Zalesov, A. V. Dancheva, A. V. Ebel', E. D. Ebel'// Lesnoy Zhurnal [Russian Forestry Journal]. 2016. Vol. 3 (351). P. 21-30.

10. Dancheva A. V., Pankratov V. K. Evaluation of Thinning Efficiency in Pineries of Dry Forest Sites of the Kazakh Uplands // Lesnoy Zhurnal [Russian Forestry Journal]. 2021. Vol. 2. P. 45-55. DOI: 10.17238/0536-10362021-2-45-55.

11. Afforestation experience in dry festuca-feather grass steppe of the Northern Kazakhstan / S. V. Zalesov, Zh. O. Suyundikov, A. V. Dancheva, A. N. Rakhimzhanov, M. R. Razhanov // Protective afforestation, land reclamation, problems of agroecology and agriculture in the Russian Federation: materials of the International Scientific and Practical Conference dedicated to the 85th anniversary of the establishment of the All-Russian Research Agromeliorative Institute. Volgograd: VNIALMI, 2016b. P. 109-113.

12. Shubin D. A., Malinovskikh A. A., Zalesov S. V. Influence of fires on the components of forest biogeocenosis in the Verkhne-Obsk pine wood stand // Vestnik of Orenburg State Agrarian University. 2013. Vol. 6 (44). P. 205-208.

13. Dancheva A. V., Zalesov S. V. Features of reforestation of burned areas in dry pine forests of the Kazakh upland in example state national nature park «Bayanaul» // Forest Engineering Journal. 2018. Vol. 224. P. $150-160$.

14. Gusev D. V. Natural regeneration of pine after ground fires on the territory of the Leningrad region // News of the Saint Petersburg State Forest Technical Academy. 2016. Vol. 215. P. 30-40. DOI: 10.21266/20794304.2016.215.30-40.

15. Dancheva A. V., Zalesov S. V. Natural reafforestation at the burnt area in belt pine forests of the Priirtyshye (for example, SFNFR «Semey ormany») // Advances in current natural sciences. 2017. Vol. 7. P. 24-29.

16. Dancheva A. V. Natural reafforestation at the burnt area in belt pine forests of the Priirtyshye // Forest operation and integrated use of wood : Collection of articles of the All-Russian scientific-practical conference. Krasnoyarsk, 2021. P. 74-79.

17. Matveev A. M., Matveev P. M. The influence of prescribed fire on regeneration of larch forests in the Middle Taiga of Evenkia // Forestry. 2006. Vol. 5. P. 7-11.

18. Portyanko A. V., Dancheva A. V., Zalesov S. V. Characteristics of crowns and trunks of trees in young pine stands, forming on burnt-out areas // Forests of Russia and agriculture in them. 2014. Vol. 4 (51). P. 14-16.

19. Assessment of cleaning cuttings efficiency in pine forests of Kazakhstan hillocks based on forestry and annual rings analyses / A. V. Dancheva, M. A. Gurskaya, S. V. Zalesov, B. M. Mukanov // Forestry. 2020. Vol. 6. P. 503-514. DOI: 10.31857/S0024114820060030.

20. Galdin V. K., Bespalenko O. N., Mikhin V. I. Fire-induced changes in coppice oak forests // Forest Engineering Journal. 2018. Vol. 4. P. 58-66. DOI: 10.12737/article_5c1a3209194713.59798372. 
21. On approval of the List of forest - growing zones of the Russian Federation and the List of Forest Areas of the Russian Federation : Ministry of Natural Resources and Ecology of the Russian Federation No. 367 : published on 18.08.2014 : ed . from 19.02.2019 : Registered with the Ministry of Justice of Russia : 29.09.2014 No. 34186 // Consultant plus. 2019. 32 p. URL: https://www.consultant.ru (Accessed 08.09.2021).

22. Dancheva A. V., Zalesov S. V. Ecological monitoring of recreational forest stand: a study guide. Yekaterinburg : Ural State Forest Engineering University (USFEU), 2015. - 152 p.

23. On approval of the Rules of Reforestation, the composition of the reforestation project, the procedure for developing a reforestation project and Making changes to it : Order of the Ministry of Natural Resources and Ecology of the Russian Federation No. 1014 : issued on 04.12.2020 : Registered with the Ministry of Justice of Russia on 18.12.2020 N 61556 // Consultant Plus. 2020. 28 p. URL: https://www.consultant.ru (Date of application 08.09.2021).

\section{Информация об авторах}

А. А. Носов - бакалавр;

А. В. Данчева - доктор сельскохозяйственных наук, профессор.

\section{Information about the authors}

A. A. Nosov-student;

A.V. Dancheva - doctor of agricultural sciences, professor.

Статья поступила в редакиию 07.09.2021; принята к публикации 10.09.2021.

The article was submitted 07.09.2021; accepted for publication 10.09.2021.

Рецензент: Кожевников А. П., доктор сельскохозяйственных наук, доцент, ФГБОУ науки «Ботанический сад» УрО РАН.

Reviewer: Kozhevnikov A. P., Doctor of Agricultural Sciences, Associate Professor, Federal State Budgetary Educational Institution of Science «Botanical Garden», Ural Branch of the Russian Academy of Sciences. 